Brieger, E. M. \& Glauert, A. M. (1952). J. gen. Microbiol. 7, 287-294.

\title{
A Phase-contrast Study of Reproduction in Mycelial Strains of Avian Tubercle Bacilli
}

\author{
By E. M. BRIEGER AND AUDREY M. GLAUER'T* \\ Papworth Hospital and Strangeways Research Laboratory, Cambridge
}

SUMMARY: The reproductive processes occurring in mycobacteria were studied in mycelial strains of avian tubercle bacilli and the developments recorded by phasecontrast microscopy. Three main developments were traced: (1) Disintegrating mycelial branches release micro-rods (as small as $0 \cdot 2 \mu$.), which later elongate into bacillary forms. (2) Parts of some mycelia produce filamentous sprouts which grow into entangled nests of filaments, and finally give rise to spherical colonies of short rods. (3) Some mycelial branches become swollen and very dense. Later they become more transparent and parallel rows of filaments are revealed lying orientated along the length of the branches. The typical morphology of orientated and non-orientated growth is explained with reference to the modes of development. Growth is preceded by a stage of mycelial proliferation, which is mainly non-acid-fast, but results in microcolonies of the normal acid-fast rod. The relation between some atypical structures and $\mathbf{L}$-forms is discussed.

In previous publications (Brieger, 1945; Brieger \& Fell, 1945, 1946; Brieger \& Robinow, 1947), evidence was submitted to show that the mycelia often seen in cultures of avian strains of tubercle bacilli, and usually described as branching forms, are not a mere abnormality of growth. Warm stage observation of living cultures made with the ordinary microscope showed how some of the filaments grew by budding, branching and elongation to form complex mycelial structures (Brieger \& Fell, 1945). Chromatinic structures were demonstrated using the acid-Giesma stain, and their presence indicated that reproductive processes were taking place in the mycelial forms (Brieger \& Robinow, 1947). However, from the results obtained the relation between the mycelial and ordinary rod-shaped forms was not altogether clear. It was uncertain whether the two types merely co-existed or whether one form could develop into the other.

In the present study the phase-contrast microscope has been used to make daily observations of living material grown in coverslip cultures. The good contrast available has enabled the relationships between the various forms to be closely examined, and has revealed structural details not seen with the ordinary microscope.

\section{MATERIALS AND METHODS}

The strain used in these experiments was recovered from the liver and spleen of a tuberculous fowl in November 1950, and was kindly supplied by the Ministry of Agriculture's Research Station, Weybridge. Subcultures were made on Löwenstein's medium as shown in Table 1.

* Sir Halley Stewart Research Fellow. 
Table 1. Details of subcultures on Lörenstein's medium

\begin{tabular}{|c|c|c|c|c|}
\hline $\begin{array}{l}\text { No. of } \\
\text { subculture }\end{array}$ & $\begin{array}{c}\text { Date of } \\
\text { subeulture }\end{array}$ & $\begin{array}{c}\text { No. of } \\
\text { experiment }\end{array}$ & $\begin{array}{l}\text { Age of culture } \\
\text { when used } \\
\text { (weeks) }\end{array}$ & $\begin{array}{l}\text { Characteristies of forms in } \\
\text { starting preparations }\end{array}$ \\
\hline 1 & 24. xi. 50 & - & - & No mycelia, short rods \\
\hline 2 & $\begin{array}{l}27 . x i i .50 \\
27 . x i i .50\end{array}$ & $\begin{array}{l}\text { CG } 1 \\
\text { CG } 2\end{array}$ & $\begin{array}{l}5 \\
9\end{array}$ & $\begin{array}{l}\text { Isolated mycelia, rods predominant } \\
\text { Isolated mycelia, rods predominant }\end{array}$ \\
\hline 3 & $\begin{array}{l}\text { 19. ii. } 51 \\
\text { 19. ii. } 51\end{array}$ & $\begin{array}{l}\text { CG } 3 \\
\text { CG } 4\end{array}$ & $\begin{array}{l}3 \\
7\end{array}$ & $\begin{array}{c}\text { Isolated mycelia, rods predominant } \\
\text { Mycelia predominant }\end{array}$ \\
\hline 4 & $\begin{array}{l}\text { 7. iii. } 51 \\
\text { 7. iii. } 51\end{array}$ & $\begin{array}{l}\text { CG } 5 \\
\text { CG } 6\end{array}$ & $\begin{array}{l}7 \\
8\end{array}$ & $\begin{array}{l}\text { Mycelia predominant } \\
\text { Mycelia predominant }\end{array}$ \\
\hline
\end{tabular}

\section{Technique}

Observations were made on cover-slip cultures prepared in a similar way to tissue cultures (Strangeways, 1924). Small drops of chick embryo extract and fowl plasma were mixed on $1 \frac{1}{4}$ in. no. 0 cover-slips and spread into a circle. The excess fluid was immediately removed with a pipette so that a thin film of medium was formed before clotting occurred. A loopful of the culture was suspended in saline and the cover-slips inoculated with a thin film of the suspension. Each cover-slip was then inverted over a brass frame $(1 \mathrm{~mm}$. thick) which had previously been sealed to a thin slide and the preparation left on the bench in an inverted position for some hours. This procedure was necessary to enable the bacilli to settle on the surface of the medium: even with it the movements of the bacilli frequently made photography difficult and on some occasions the preparation had to be fixed before recordings could be made. The living cultures were incubated at $37 \cdot 5^{\circ}$ for the period of the experiment.

Observations were made with a Cooke, Troughton and Simms microscope equipped with phase-contrast condenser and objectives. A reflex camera was adapted to take photographic recordings on $35 \mathrm{~mm}$. Microfile film. Each day frequent observations were made of the preparations with the $\frac{1}{12}$ in. oilimmersion objective, and photographs taken to record all the typical forms present. This was usually continued for about 3 weeks when staining showed that acid-fast microcolonies had invariably formed. At each stage parallel cultures were fixed and stained by various methods (to be described in a later publication) and the results compared.

At intervals the microscope was placed in a hot-box and a certain field was selected and viewed continuously for several days. Experience has shown that the value of such observations is limited by the fact that developments in the selected field are not necessarily typical of developments in the culture as a whole. In one field where four small mycelia were observed for 5 days it was found that three remained unchanged throughout that time, while the fourth developed rapidly and strikingly between the 3rd and 5th days of incubation, producing a mass of fine elongated filaments. This technique gives valuable information about changes in individual organisms, but in order to obtain a correct picture of all the main developments in the culture, a method would 
have to be adopted which would enable a far larger area to be studied continuously. As the distribution of the developing microcolonies is very irregular a study of adjacent areas would not necessarily solve the problem.

\section{RESULTS}

The results of the series of experiments can be placed in two distinct groups. In Exps. CG 1-CG 3 the development was mainly non-mycelial, while in Exps. CG 4-CG 6 the mycelial growth type predominated. The final product of the two types of development was the same: microcolonies of normal acidfast rods.

Development of the Filamentous 'Type (Exps. CG1,

CG 2 AND CG 3)

The growth in the non-mycelial forms seems to follow the recognized type of bacterial multiplication. The inoculum consists mainly of small rod-shaped forms varying in size up to $1 \mu$. in length ( $\mathrm{Pl}$. 1, fig. 1). After 5-7 days' incubation at $37 \cdot 5^{\circ}$ the rods are no longer seen and the field is covered with long filaments of $8-10 \mu$. in length (Pl. 1, fig. 3). They are usually bent, vary in thickness and often have tapering or club-ends. Some are in groups and there is evidence of slight budding. Although complex mycelial structures are not present, the arrangement of the filaments is often suggestive of the mycelial form of reproduction. In fact, their method of development is very different from that of normal bacteria, and observation during the first few days of incubation shows that the final filaments are formed as a result of a germination process. The original micro-rods produce fine filamentous sprouts and in one experiment (CG 2) their appearance after $48 \mathrm{hr}$. incubation (Pl. 1, fig. 2) was similar to that seen in the streptomycetes. The sprouting filaments are bent and sometimes beaded, and possibly correspond with germination tubes.

\section{Development of the Mycelial Type (Exps. CG 4, CG 5 and CG 6)}

\section{Starting preparation of the inoculum}

In the starting preparations the picture differs from that seen in the nonmycelial cultures. Mycelial structures are now predominant, isolated rods are in the minority and many aggregates of small, dense, elements $(0 \cdot 5-1 \cdot 0 \mu$. are present ( $\mathrm{Pl}$. 1, fig. 4). These aggregates may have resulted from a sprouting or division of small rod-shaped forms, and this may account for the great variety in grouping observed. The phase-contrast microscope also reveals the presence of minute, dense and usually spherical particles. Their dense centres are near the limit of resolution of the microscope, and they are frequently surrounded by some material of less density, which may be a form of outgrowth and gives them an irregular outline.

The mycelial structures consist of filaments with a few buds and branches. They show variations in thickness and density, and vacuoles and dense swellings occur. The various branches appear to be in different stages of development, and in some cases are apparently disintegrating. 


\section{Stage of mycelial proliferation (1-5 days)}

During the following days of incubation rapid changes occur. The small elements increase markedly in number, become less dense and sometimes assume a rod-like form (Pl. 1, fig. 5). The irregular aggregates begin to contain increasing numbers of rods, and some clumps produce fine filamentous sprouts. Various changes occur simultaneously in the mycelia; they sprout fine filaments, their branches elongate, obvious internal structure is seen; they break up into fragments and they continue to grow on different levels. In the course of this development highly complex structures are formed which we have found to be characteristic of this phase of the mycelial type of growth (Pl. 1, fig. 6). They consist of a mass of entangled filaments and they are unlike anything described by earlier workers, mainly due to the fact that they are non-acidfast and do not give a clear picture when viewed unstained in transmitted light. However, as will be shown in a later communication, they form the non-acid-fast matrix within which the acid-fast elements may regerminate. Forms also occur which bear some resemblance to the zooglea of AlexanderJackson (1945) and the L-forms of Klieneberger-Nobel (1951) (Pl. 4, figs. 17, 18). In our cultures similar forms seem to have some relation to the mycelial type of reproduction.

\section{Stage of development of microcolonies}

Development of spherical colonies. The first definite stage in the development of spherical colonies of bacilli is the formation of small nests of fine filaments (Pl. 2, fig. 9). These are seen on about the 5th day of incubation and result from the proliferation of the sprouts present after $24 \mathrm{hr}$. They originate either in dense parts of the mycelia (Pl. 2, fig. 10), or in the aggregates of small organisms (PI. 2, fig. 9). The filaments grow out in all directions and give the resulting structures a disorientated appearance. In some microcolonies the angular growth type (Ørskov, 1923) is very striking. At later stages the continued filamentous proliferation transforms the nests into small microcolonies which begin to assume a spherical shape (Pl. 2, fig. 11). Owing to their increasing thickness it now becomes difficult to focus all the various levels, and individual filaments are not easily distinguishable. The centres of the clumps acquire a granular appearance ( $\mathrm{Pl} .2$, fig. 12) due to the marked beading of the component filaments. Finally, after about 18 days, these filaments separate from the periphery of the colony. Sometimes the association of the final colony with an original mycelium is still clear (Pl. 2, fig. 11). This type of microcolony formation is mainly confined to the more fluid parts of the preparations.

Development of cords. The development of cords begins after about 5 days when some mycelial branches become very dense and later give rise to parallel rows of bacillary forms ( $\mathrm{Pl}$. 3, fig. 13). During the following days of incubation some of these cords grow into long strands of bacilli, and after about 19 days the rods separate out and are finally released. These cordformations predominate in the drier parts of the cultures, although they are 
also seen associated with the spherical colonies (Pl. 3, fig. 14). It seems likely that the two types of growth can take origin from different sections of the original mycelial complex.

Production of micro-rods. In parallel with these two types of development micro-rods are seen to develop within some of the mycelia. Other mycelia disintegrate and directly release large numbers of micro-rods containing bipolar densities (Pl. 2, fig. 7). These later elongate into denser, short filaments, so that colonies of bacilli appear. The form of the original mycelium is often still apparent (Pl. 2, fig. 8).

\section{Structure of the final bacilli}

It is remarkable that these different types of mycelial growth all result in the formation of the typical bacillary form (Pl. 4, figs. 15, 16). The bacilli vary in length up to about $2 \mu$. and often appear to divide by a process of simple fission. Some appear beaded in these living cultures (Pl. 4, fig. 15) and are associated with bipolar micro-rods.

From stained preparations it can be shown that the final products of all these three types of development are acid-fast, although the preceding mycelial forms are frequently non-acid-fast.

\section{DISCUSSION}

In this study phase-contrast microscopy has provided evidence of similarities between reproduction in avian strains of tubercle bacilli and in the ray fungi (Orskor, 1923). A germination process was seen to occur in the early stages of development. Germination of granular forms has also been described by Sweaney (1928), Alexander-Jackson (1945) and Nedelkovitch (1950) in human-type bacilli. Whether the fine sprouts formed are true germination tubes remains uncertain; they may be merely filamentous outgrowths from resting cells.

In 1945, Alexander-Jackson described zoogleal forms in cultures of human tubercle bacilli. In our cultures similar forms were present (Pl. 4, figs. 17, 18) and were related to mycelial fragments containing globoid bodies. Klieneberger-Nobel (1951) has referred to the possibility that L-forms occur in the reproductive cycle of tubercle bacilli, but so far we have no evidence to show that the forms we have seen develop in a way similar to L-forms.

Beading was seen in living cultures in the mycelial branches and in the final bacilli (Pl. 4, fig. 15). Their nature is uncertain but they may correspond to the chromatinic bodies described by Brieger \& Robinow (1947); they cannot be mere artefacts as suggested by Porter \& Yegian (1945). These beads gave rise to the rod-shaped elements which developed within the mycelial branches. Sometimes a whole section of the mycelium broke up into a mass of micro-rods (Pl. 2,' figs. 7, 8). Phase-contrast observation showed them to be bipolar rods and not granules. They were sometimes as small as $0.2 \mu$. in length and thus comparable in size with psittacosis bodies and the larger rickettsias. If only the polar densities were detected the rods 
might be described as granules (Kahn, 1932), and they may easily be the elements assumed by Wyckoff (1934) to be merely short segments of rods.

In following the development of the mycelial forms we have seen how they give rise to acid-fast microcolonies of two types. These correspond closely to those described recently by Middlebrook (1950) in human bacilli. We could trace the different developments that lead to the production of the two types of microcolony. The filaments in the spherical colonies appear to be free to grow in any direction without restraint, and this results in a completely disorientated arrangement in the developing colonies. In contrast, the bacilli forming the cords appear to be constrained to lie in parallel rows, and are originally packed within dense mycelial branches. Presumably some substance similar to Bloch's 'cord factor' (1950) holds them together. The striking fact in the present observations is that the two types of colony can be seen to develop from different parts of the same mycelial structure.

The shape of the bacilli in the various stages of development differed considerably from the mature (acid-fast) rod shown in Pl. 4, fig. 15. They varied in density and in particular the bacilli at the edges of the cord-like colonies had the same 'pin-like terminal sprouts' described by Brieger $\&$ Fell (1946).

The amazing variety of forms revealed by the phase-contrast microscope when used to study living cultures of avian tubercle bacilli explains the pleomorphism first described by Maffucci (1892). By this method of daily observation it was possible to demonstrate the relation of these forms to each other and their place in the reproductive process. However, the present results do not enable us to classify the avian bacillus among the actinomycetes, streptomycetes or nocardias with which they have often been identified. In spite of certain similarities the differences are even more striking, and it may be that the development we have described is a distinguishing feature of the mycobacteria.

\section{REFERENCES}

Alexander-Jackson, E. (1945). A hitherto undemonstrated Zoogleal form of Mycobacterium tuberculosis. Ann. N.Y. Acad. Sci. 46, 127.

Bloch, H. (1950). Enzymatic characteristics of suspensions of different mycobacteria. Amer. Rev. Tuberc. 61, 270.

BriEger, E. M. (1945). Observations on the species pathogenicity of the tubercle bacillus in intra-amniotic infection. J. Paih. Bact. 57, 282.

Brieger, E. M. \& Fell, H. B. (1945). Warm-stage observations on the initial development of the avian tubercle bacillus cultivated in embryo extract. J. Hyg., Camb., 44, 158.

Brieger, E. M. \& Fell, H. B. (1946). Warm-stage observations on the development of pseudo-mycelia in cultures of avian tubercle bacilli grown in dilute embryo extract. J. Hyg., Camb. 44, 256.

Brieger, E. M. \& Robinow, C. F. (1947). Demonstration of chromatinic structures in avian tubercle bacilli in the early stages of development. J. Hyg., Camb. 45, 413.

KAHN, M. C. (1932). Weitere Bemerkungen zur morphologischen Untersuchung über den Entwicklungszyklus der Einzelzelle des Tuberkelbazillus. Zbl. Bakt. (1. Abt. Orig.), 125, 451. 
Klieneberger-Nobel, E. (1951). Filterable forms of bacteria. Bact. Rev. 15, 77. Maffuccr, A. (1892). Die Hühnertuberkulose. Z. Hyg. InfektKr. 11, 445.

Middlebrook, G. (1950). Recent advances in bacteriological research in tuberculosis. Recent Adv. Tuberc. Res. 3, 132.

Nedelkovitch, J. (1950). Mode de multiplication du bacilli de Koch. Morphologie du bacilli et de ses colonies. Quelques sources d'erreurs. Ann. Inst. Pasteur, 78,177 .

Ønskov, J. (1923). Investigations into the Morphology of the Ray Fungi. Copenhagen: Levin and Munksgaard.

Porter, K. R. \& Yegian, D. (1945). Some artifacts encountered in stained preparations of tubercle bacilli. II. Much granules and beads. J. Bact. 50, 263.

Strangeways, T. S. P. (1924). The Technique of Tissue Culture 'in vitro'. Cambridge: Heffer and Sons Ltd.

Sweaney, H. (1928). The granules of the tubercle bacillus. Amer. Rev. Tuberc. $17,53$.

Wyckoff, R. W. G. (1934). A micro-motion picture study of the growth of tubercle bacilli from cold-blooded animals. Amer. Rev. Tuberc. 24, 389 .

\section{EXPLANATION OF PLATES}

Cover-slip cultures of Mycobacterium avium grown on embryo-extract plasma clots and photographed with phase-contrast microscopy. Incubated at $37 \cdot 5^{\circ}$.

\section{Plate 1}

Filamentous type of grozeth

Fig. 1. Starting preparation of a 5 -week old culture (CG 1). Filamentous growth type. Small rod-shaped forms and isolated mycelial elements. $(\times 4000$. $)$

Fig. 2. After $48 \mathrm{hr}$. incubation (CG 2). Process of germination. $(\times \mathbf{2 5 0 0}$.)

Fig. 3. After $\tau$ days incubation (CG 3). Filaments resulting from elongation of elements of Fig. 2. Note branched form and the grouping of the filaments. $(\times 2500$.)

\section{Mycelial type of growth}

Fig. 4. Starting preparation of 7-week old culture (CG 5). Branched mycelial form, aggregates of small elements and minute spherical particles (granular forms). $(\times 2500$.

Fig. 5. 24 hr. (CG 5). Note the presence of micro-rods. $(\times 2500$.)

Fig. 6. 5 days (CG 5). Complex structure characteristic of mycelial phase of growth. Results from proliferation of original mycelial elements. $(\times \mathbf{2 5 0 0 .})$

$$
\text { Plate } 2
$$

Fig. 7. 8 days (CG 5). Mycelium disintegrating and releasing micro-rods. $(\times 2500$.)

Fig. 8. 14 days (CG 5). Micro-rods of fig. 7 after elongation. $(\times 2500$.)

Fig. 9a,b. 5 days (CG 5). First stage in spherical colony formation. Small nests of fine filaments. Note 'angular growth type'. $(\times \mathbf{2 5 0 0}$. $)$

Fig. 10. 5 days (CG 5). Sprouting mycelium beginning to form small nest of filaments. Other parts of mycelium becoming swollen and dense. $(\times \mathbf{2 5 0 0}$.)

Fig. 11. 13 days (CG 5). At a more advanced stage the microcolony assumes a spherical shape. Note rod-shaped inclusions within original mycelium. $(\times \mathbf{2 5 0 0}$.)

Fig. 12. 13 days (CG 5). Fully formed spherical colonies. Note beading of filaments giving a granular appearance. The elements are now strongly acid-fast. $(\times 2500$.

\section{Plate 3}

Fig. 13. 6 days (CG 5). Longitudinal splitting of dense, swollen filaments resulting in cord formation. $(a) \times 4000 ;(b) \times 2500$.

Fig. 14. 13 days (CG 5). Association of a cord formation and spherical colony. They have originated in different parts of the same original mycelium. $(\times 4000$. 
Plate 4

Fig. 15. 18 days (CG 5). Typical bacillary forms resulting from mycelial development. Note beaded elements and small, bipolar rods. $(\times 4000$.

Fig. 16. 19 days (CG 5). Typical bacillary forms. Disintegrated mycelium still visible in background. Note that some of the rods are dividing by simple fission. $(\times 4000$. $)$

Fig. 17. 6 days (CG 5). Zoogleal forms showing pseudo-mycelial structure. $(\times 4000$.)

Fig. 18. 8 days (CG 5). Zoogleal or L-form. Dense bodies in amorphous background. $(\times 4000$.

(Received 25 March 1952) 
Journal of General Microbiology, Vol. 7, Nos. 3 and 4

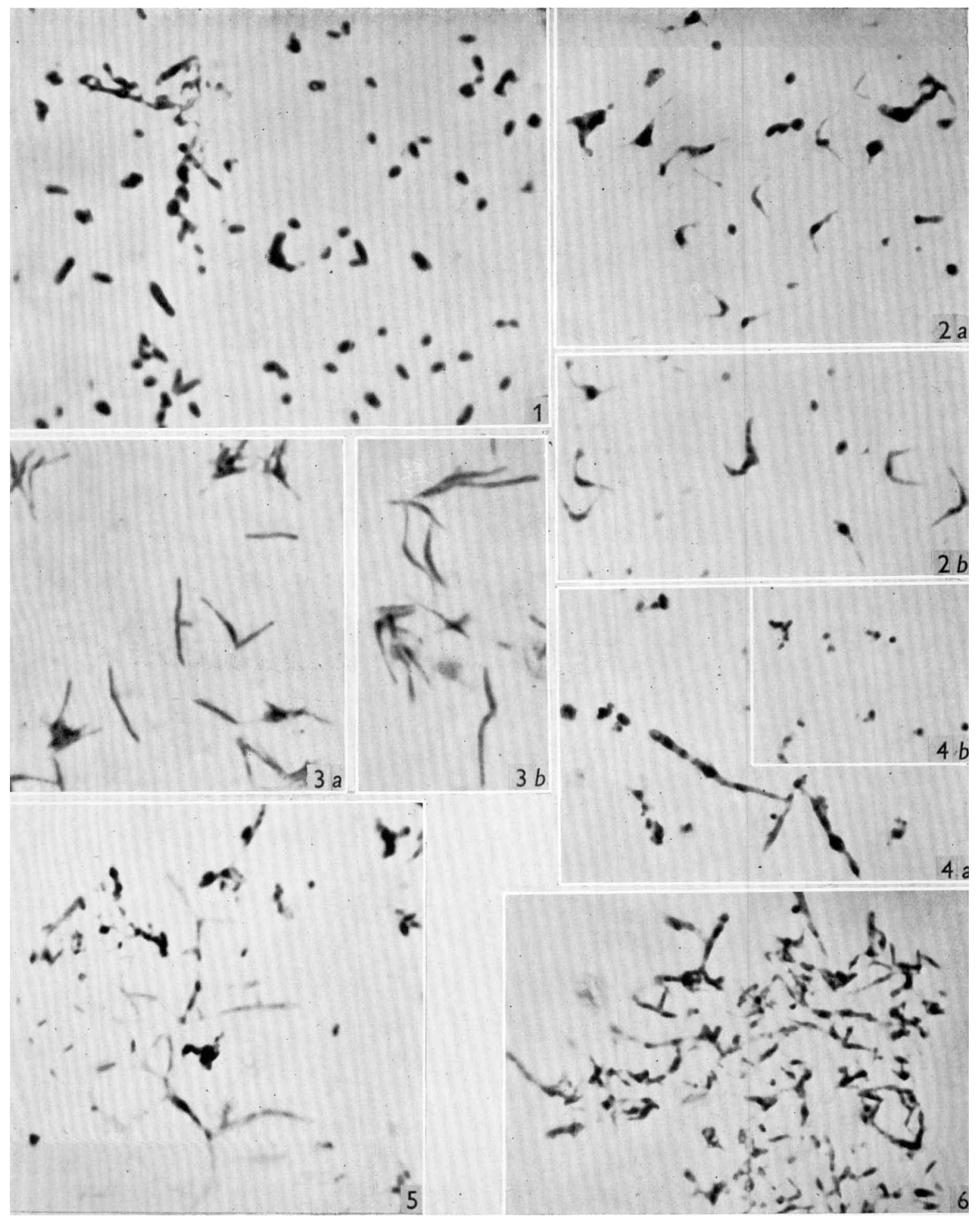

E. M. Brieger \& Audrey M. Glauert-Reproduction of avian tubercle bacilli. Plate 1 
Journal of General Microbiology, Vol. 7, Nos. 3 and 4

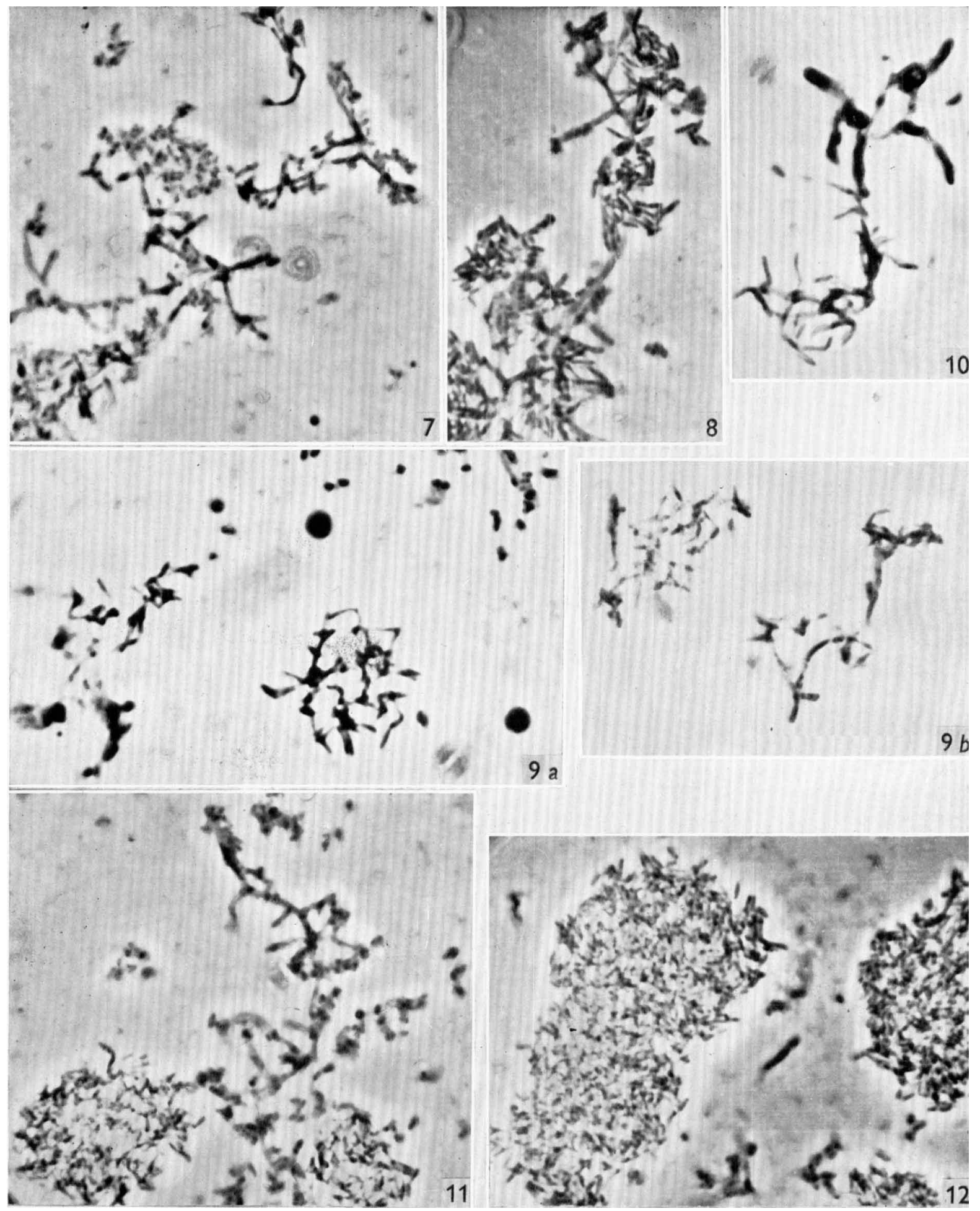

E. M. Brieger \& Audrey M. Glauert-Reproduction of avian tubercle bacilli. Plate 2 
Journal of General Microbiology, Vol. 7, Nos. 3 and 4

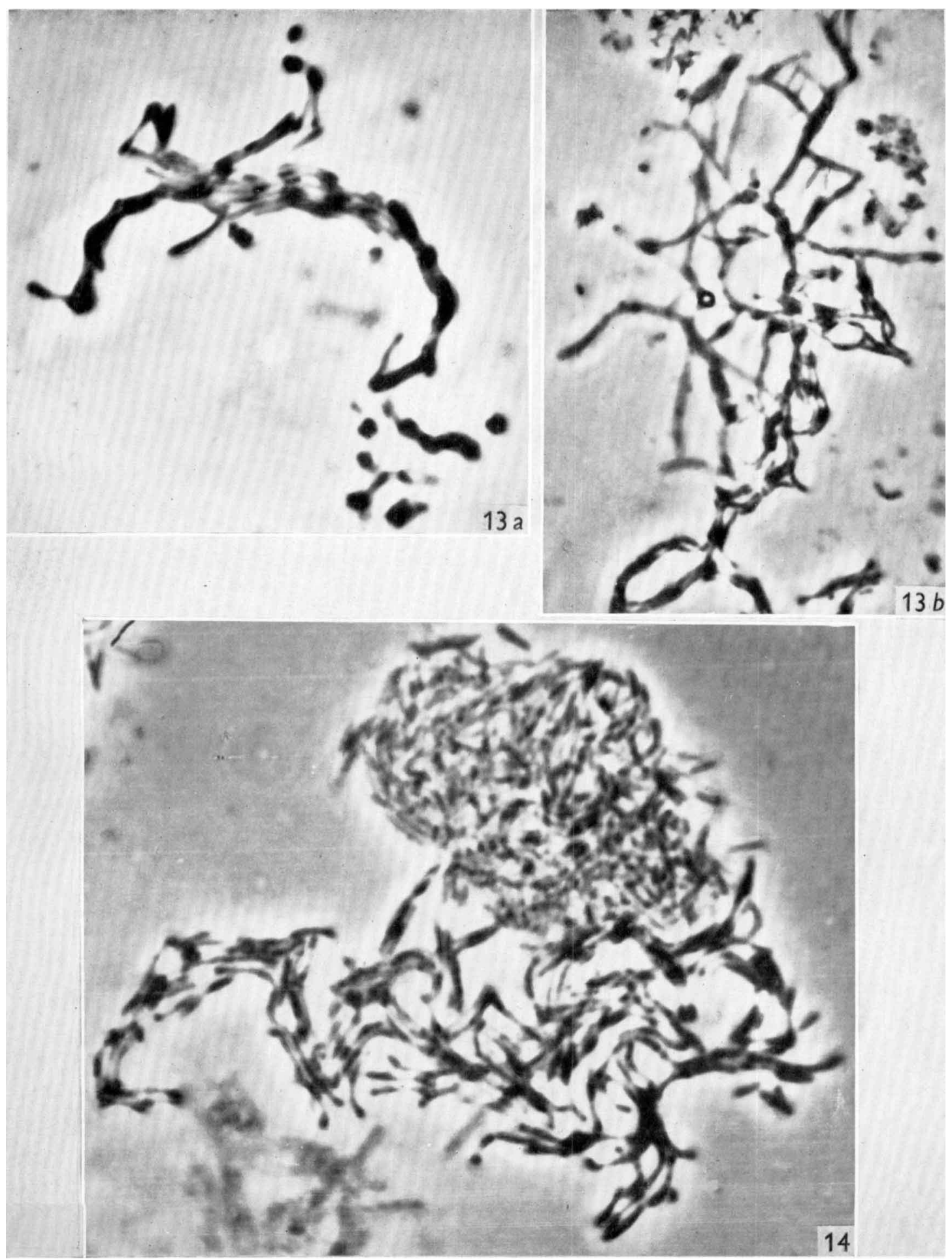

E. M. Brigger \& Audrey M. Glauert-Reproduction of avian tubercle bacilit. Piate 3 
Journal of General Microbiology, Vol. 7, Nos. 3 and 4

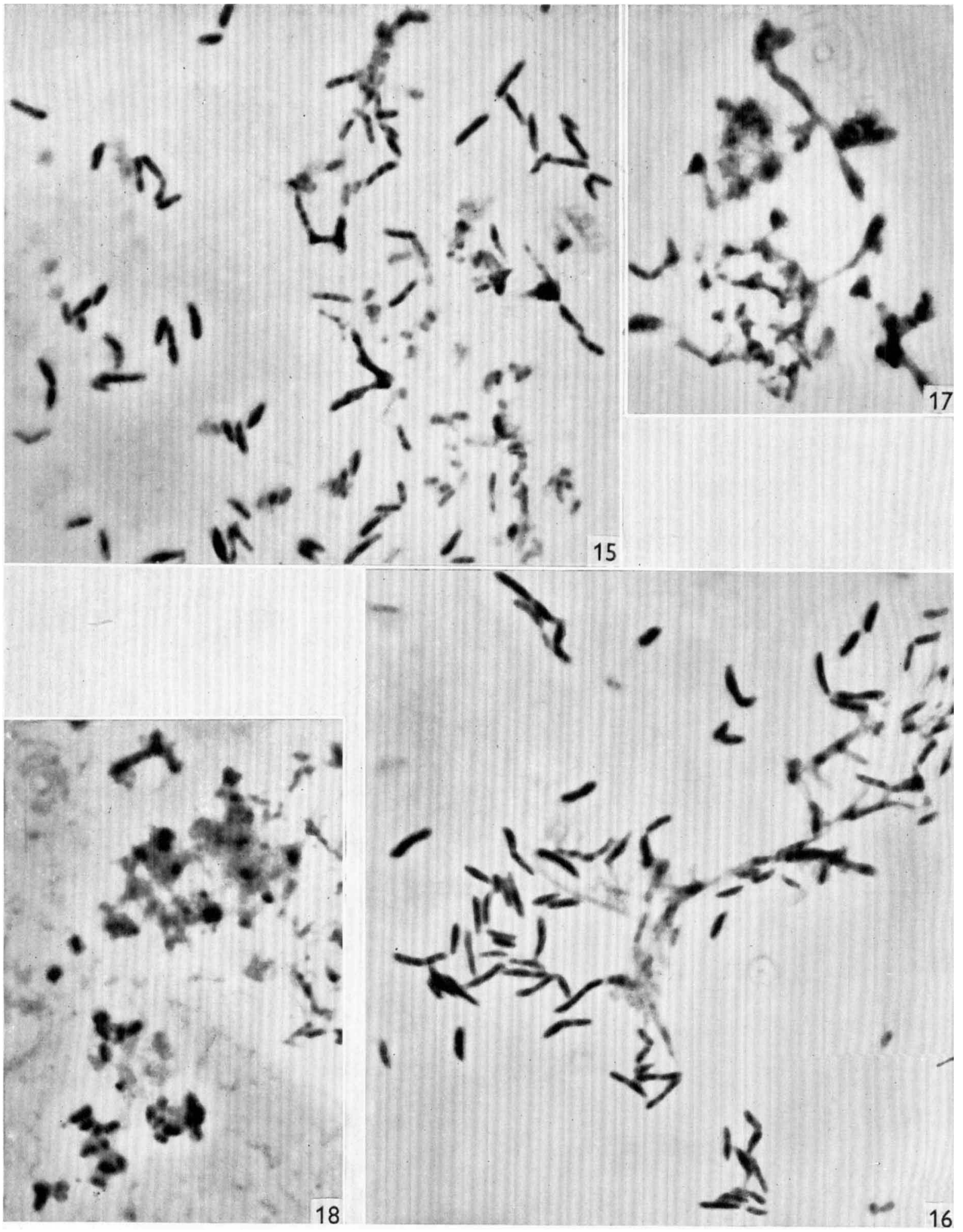

E. M. Brieger \& Audrey M. Glauert-Reproduction of avian tubercle bacilli. Plate 4 